\title{
Antimycobacterial neolignans isolated from Aristolochia taliscana
}

\author{
Rosalba León-Díaz, Mariana Meckes', Salvador Said-Fernández², Gloria Maria Molina-Salinas², \\ Javier Vargas-Villarreal ${ }^{2}$, Javier Torres ${ }^{3}$, Julieta Luna-Herrera ${ }^{4}$, Adelina Jiménez-Arellanes ${ }^{1 /+}$ \\ 'Unidad Investigación Médica en Farmacología de Productos Naturales ${ }^{3}$ Unidad de Investigación Médica en Enfermedades Infecciosas y \\ Parasitarias, Hospital de Pediatría, Instituto Mexicano del Seguro Social, Centro Médico Nacional Siglo XXI, Av. Cuauhtémoc 330, \\ Col. Doctores, CP 06720, Delg. Cuauhtémoc, México DF, México ²División de Biologia Celular y Molecular, Centro de Investigacion \\ Biomedica del Noroeste, Instituto Mexicano del Seguro Social, Nuevo Leon, México ${ }^{4}$ Laboratorio de Inmunoquímica II, Departamento \\ de Inmunoquímica, Escuela Nacional de Ciencias Biológicas, Instituto Politécnico Nacional, México DF, México
}

Tuberculosis (TB - Mycobacterium tuberculosis) is an ancient infectious disease that has appeared once again as a serious worldwide health problem and now comprises the second leading cause of death resulting from a single infection. The prevalence of multidrug resistance (MDR) TB is increasing and therapeutic options for treatment are not always accessible; in fact, some patients do not respond to the available drugs. Therefore, there is an urgent need to develop novel anti-TB agents. The aim of the present study was to screen extracts of Aristolochia taliscana, a plant used in traditional Mexican medicine to treat cough and snake bites, for antimycobacterial activity. The hexanic extract of $\mathrm{A}$. taliscana was tested by microdilution alamar blue assay against Mycobacterium strains and bioguided fractionation led to the isolation of the neolignans licarin A, licarin B and eupomatenoid-7, all of which had antimycobacterial activity. Licarin $A$ was the most active compound, with minimum inhibitory concentrations of 3.12-12.5 $\mu \mathrm{g} / \mathrm{mL}$ against the following M. tuberculosis strains: H37Rv, four mono-resistant H37Rv variants and 12 clinical MDR isolates, as well as against five non-tuberculous mycobacteria (NTM) strains. In conclusion, licarin A represents a potentially active anti-TB agent to treat MDR M. tuberculosis and NTM strains.

Key words: antimycobacterial neolignans - A. taliscana - M. tuberculosis H37Rv - MDR M. tuberculosis non-tuberculous mycobacteria

Medicinal plants are an important natural source of novel leads in the field of antimycobacterial therapeutics (Cantrell et al. 2001, Copp \& Pearce 2007, Gutierrez-Lugo \& Bewley 2008). According to ethnobotanical data, some species of Aristolochia, such as Aristolochia elegans and Aristolochia grandiflora have been widely utilized in Mexican traditional medicine to treat cough (Diaz 1976). A preliminary biological evaluation of the hexanic extract from Aristolochia taliscana Hook roots showed that it possessed an in vitro antimycobacterial effect against Mycobacterium tuberculosis H37Rv and Mycobacterium avium [minimum inhibitory concentrations $\left.\left(\mathrm{MIC}^{\prime} \mathrm{s}\right)=50 \mu \mathrm{g} / \mathrm{mL}\right]$. The plant is commonly known in Mexico as guaco or raiz de guaco and neolignans with antiprotozoal activity have already been identified in the species (Enriquez et al. 1984, Abe et al. 2002).

In recent years, the number of patients with tuberculosis (TB) has increased rapidly due, in part, to the appearance of multidrug-resistant (MDR) and extensively drug-resistant (XDR) strains in both developing and developed countries. One-third of the world's population is currently infected with M. tuberculosis

Financial support: Instituto Mexicano del Seguro Social (FOFOI FP2003-009, 2005/1/I/102), CONACYT (to RLD)

+ Corresponding author: adelinaj@servidor.unam.mx

Received 4 June 2009

Accepted 4 August 2009 and approximately $10 \%$ of these cases will develop clinical manifestations, particularly those patients with compromised immunological systems. The AIDS/HIV pandemic has contributed to the worsening of the problem; in fact, about $30 \%$ of registered mortality has been associated with TB, especially in developing countries (Jain \& Mondal 2008, Rivers \& Mancera 2008). Patients with AIDS are also susceptible to becoming infected with non-tuberculous mycobacteria (NTM) such as $M$. avium (Rodriguez et al. 2006). It is estimated that the worldwide prevalence of MDR-TB is about 3.2\% and that $6.6 \%$ of these cases are XDR-TB (Rivers \& Mancera 2008). The emergence of XDR-TB strains constitutes a serious health problem because, at present, there is no pharmaceutical alternative for treating patients infected with such strains (Tomioka 2006, Zager \& McNerney 2008). Consequently, novel drugs to treat or prevent the disease are urgently needed (O'Brien \& Spigelman 2005, Gutierrez-Lugo \& Bewley 2008).

The aim of the present paper was to isolate and structurally characterize $A$. taliscana hexane-extract compounds that possessed activity against $M$. tuberculosis H37Rv, mono-resistant variants of H37Rv, MDR M. tuberculosis clinical isolates and NTM.

\section{MATERIALS AND METHODS}

Plant materials - A. taliscana roots were purchased at a medicinal plant market in city of Mexico, Mexico. The plant material was compared with the botanical specimen deposited at the Herbarium of the Instituto Mexicano del Seguro Social and a voucher was deposited under code 1106. 
Extraction and isolation - Powdered air-dried roots $(1.5 \mathrm{~kg})$ were macerated $(3 \times 48 \mathrm{~h})$ with $12 \mathrm{~L}$ of $\mathrm{n}$-hexane. The extract was filtered and evaporated in vacuo to yield $33 \mathrm{~g}$ of the crude extract. Open column chromatography (CC) was performed employing the silica gel $60 \mathrm{GF}_{254}$ (70-230 mesh, Merck) as the stationary phase and silica gel $60 \mathrm{~F}_{254}$ pre-coated aluminium plates $(0.2$ $\mathrm{mm}$, Merck) for analytical and preparative thin-layer chromatography (TLC) analysis. Spots were visualized by spraying with a $10 \%$ solution of $\mathrm{H}_{2} \mathrm{SO}_{4}$ followed by heating the plates at $100^{\circ} \mathrm{C}$.

For silica gel $\mathrm{CC}$, the extract $(15 \mathrm{~g})$ was fractionated by eluting with $n-\mathrm{Hex}: \mathrm{CHCl}_{3}(100 \rightarrow 0)$ and $\mathrm{CHCl}_{3}: \mathrm{MeOH}$ $(100 \rightarrow 0) ; 72$ fractions $(250 \mathrm{~mL}$ each) were obtained. The primary fractions (F1-F15) were combined according to the results from the TLC analysis. All primary fractions were tested for antimycobacterial activity.

From the active fraction F5-F7, $975 \mathrm{mg}$ of white needles with a melting point (m.p.) of $82-86^{\circ} \mathrm{C}$ (lit. m.p. $89-90^{\circ} \mathrm{C}$ ) crystallized. The compound was identified as licarin B (1) and was also detected in fractions F8-F11. Fractions F8-F11 (2.5 g) were re-chromatographed on $\mathrm{CC}$ using silica gel (75 g) with a solvent gradient of n$\mathrm{Hex}: \mathrm{CHCl}_{3}(100 \rightarrow 0)$ and $\mathrm{CHCl}_{3}: \mathrm{MeOH}(100 \rightarrow 0)$. This process yielded 14 secondary fractions (FA-FN) of 150 $\mathrm{mL}$ each. Secondary fraction FD yielded $40 \mathrm{mg}$ of 1 and fraction FF (400 mg) was re-chromatographed in CC and eluted with n-Hex: $\mathrm{CHCl}_{3}(100 \rightarrow 0)$ and $\mathrm{CHCl}_{3}: \mathrm{MeOH}$ $(100 \rightarrow 0)$ to obtain eight tertiary fractions Fa-Fh. The isolated maroon-coloured powder ( $80 \mathrm{mg}$ ) from $\mathrm{Fc}-\mathrm{Fe}$ was characterized as eupomatenoid-7 (2) with an m.p. of $100-104^{\circ} \mathrm{C}$ (lit. m.p. $105-106^{\circ} \mathrm{C}$ ).

The secondary fraction FJ (300 mg) was further rechromatographed on $\mathrm{CC}$ utilizing n-Hex: $\mathrm{CHCl}_{3}$ and $\mathrm{CHCl}_{3}$ as elution systems. Nine $50 \mathrm{~mL}$ tertiary fractions (Fa'-Fi') were obtained. From Fb', $196 \mathrm{mg}$ of a white product was obtained by crystallization with an m.p. of $107-110^{\circ} \mathrm{C}$ (lit. m.p. $133-134^{\circ} \mathrm{C}$ ), which was identified as licarin A (3).

Chemical characterization - Chemical characterization of the isolated neolignans was determined by ${ }^{1} \mathrm{H}-\mathrm{NMR}$ (Eclipse $300 \mathrm{Jeol}, 300 \mathrm{MHz}$ ) and ${ }^{13} \mathrm{C}-\mathrm{NMR}$ (Variant Unity, $300 \mathrm{MHz}$ ) using tetramethylsilane as an internal standard in $\mathrm{CDCl}_{3}$. Electron impact-mass spectra were obtained on a Jeol AX-505 HA mass spectrometer at $70 \mathrm{eV}$. Infrared (IR) spectra on film over $\mathrm{NaCl}$ in a Bruker model Tensor 27 spectrometer, optical rotation in a Perkin Elmer model 345 polarimeter at $25^{\circ} \mathrm{C}$ using a sodium lamp (589 nm) and m.p. in a Fisher-Johns apparatus. All the spectroscopic data $\left({ }^{1} \mathrm{H}\right.$ and $\left.{ }^{13} \mathrm{C}-\mathrm{NMR}\right)$ of each compound were compared with those previously reported in the literature (Enriquez et al. 1984) and are described in Tables I, II.

Licarin $B$ (1) - White needles soluble in $\mathrm{CHCl}_{3}$, m.p. $82-86^{\circ} \mathrm{C},[\alpha]_{\mathrm{D}}{ }^{25^{\circ} \mathrm{C}}=-0.262(\mathrm{MeOH})$, IR: $v_{\max } 2900,1600$ and 1050-1200. IE-MS: $m / z$ (rel. int.) 324 [M $\left.\mathrm{M}^{+}(100)\right], 309$ (12), 293 (8), 278 (28), 202 (6), 135 (20), 121 (8), 91 (7), 77 (14) and 46(5).

TABLE I

${ }^{1} \mathrm{H}-\mathrm{NMR}$ spectral data $(\delta$ scale) and coupling constant $(\mathrm{J}, \mathrm{Hz})$ for compounds 1-3 isolated from Aristolochia taliscana

\begin{tabular}{|c|c|c|c|}
\hline Proton & Compound 1 & Compound 2 & Compound 3 \\
\hline 2 & $\begin{array}{c}5.09 \\
\left(\mathrm{~J}_{2-3}=8.97\right)\end{array}$ & - & $\begin{array}{c}5.09 \\
\left(\mathrm{~J}_{2-3}=9.5\right)\end{array}$ \\
\hline 3 & $3.37-3.45$ & - & $3.39-3.47$ \\
\hline 4 & $\begin{array}{l}6.72-6.79 \\
\left(J_{4-6}=1.5\right)\end{array}$ & $\begin{array}{c}7.03 \\
\left(\mathrm{~J}_{4-6}=1.5\right)\end{array}$ & $\begin{array}{c}6.77 \\
\left(\mathrm{~J}_{4-6}=1.5\right)\end{array}$ \\
\hline 6 & 6.79 & $\begin{array}{c}6.82 \\
\left(\mathrm{~J}_{6-4}=1.5\right)\end{array}$ & $\begin{array}{c}6.77 \\
\left(\mathrm{~J}_{4-6}=1.5\right)\end{array}$ \\
\hline $2^{\prime}$ & $\begin{array}{c}6.92 \\
\left(\mathrm{~J}_{2^{\prime}-5^{\prime}}=1.7\right)\end{array}$ & $\begin{array}{c}7.01 \\
\left(\mathrm{~J}_{2^{\prime}-5^{\prime}}=2.0\right)\end{array}$ & $\begin{array}{c}6.97 \\
\left(\mathrm{~J}_{2^{\prime}-5^{\prime}}=1.9\right)\end{array}$ \\
\hline $5^{\prime}$ & $\begin{array}{c}6.87 \\
\left(\mathrm{~J}_{5^{\prime}-6^{\prime}}=8.3\right)\end{array}$ & $\begin{array}{c}7.25-7.32 \\
\left(\mathrm{~J}_{5^{\prime}-6^{\prime}}=8.2\right)\end{array}$ & $\begin{array}{c}6.89 \\
\left(\mathrm{~J}_{5^{\prime}-6^{\prime}}=8.3\right)\end{array}$ \\
\hline $6^{\prime}$ & $\begin{array}{c}6.87 \\
\left(\mathrm{~J}_{6^{\prime}-5^{\prime}}=8.3, \mathrm{~J}_{2^{\prime}-6^{\prime}}=0-44\right)\end{array}$ & $\begin{array}{c}6.98 \\
\left(\mathrm{~J}_{5^{\prime}-6^{\prime}}=8.2, \mathrm{~J}_{2^{\prime}-6^{\prime}}=0.6\right)\end{array}$ & $\begin{array}{c}6.89 \\
\left(\mathrm{~J}_{5^{\prime}-6^{\prime}}=8.3, \mathrm{~J}_{2^{\prime}-6^{\prime}}=0.44\right)\end{array}$ \\
\hline$\alpha$ & 6.35 & 6.49 & 6.36 \\
\hline$\beta$ & $6.04-6.15$ & $6.15-6.27$ & $6.04-6.16$ \\
\hline$\gamma$ & 1.86 & 1.90 & 1.86 \\
\hline $\mathrm{CH}_{3}$ & 1.37 & 2.40 & 1.37 \\
\hline $\mathrm{OCH}_{3}$ & 3.88 & 3.97 & 3.87 \\
\hline $\mathrm{OCH}_{3}$ & - & 4.03 & 3.89 \\
\hline $\mathrm{OCH}_{2} \mathrm{O}$ & $5-95$ & - & - \\
\hline $\mathrm{OH}$ & - & 5.75 & 5.62 \\
\hline
\end{tabular}

all compounds had $\mathrm{J}_{\alpha-\beta}=15.87 \mathrm{~Hz}, \mathrm{~J}_{\alpha-\gamma}=1.7 \mathrm{~Hz}$ and $\mathrm{J}_{\beta-\gamma}=6.5 \mathrm{~Hz}$. Compounds 1 and 3 had $\mathrm{J}_{3-\mathrm{Me}}=6.8 \mathrm{~Hz}$. Record in $\mathrm{CDCl}_{3}$ at $300 \mathrm{MHz}$ 
TABLE II

${ }^{13} \mathrm{C}$-NMR spectral data for compounds $1-3$ in $\mathrm{CDCl}_{3}$ isolated from Aristolochia taliscana

\begin{tabular}{lccc}
\hline Carbon & Compound 1 & Compound 2 & Compound 3 \\
\hline 2 & 93.38 & 151.48 & 93.77 \\
3 & 45.75 & 110.19 & 45.61 \\
$3^{\mathrm{a}}$ & 133.08 & 133.05 & 133.28 \\
4 & 113.34 & 109.16 & 113.32 \\
5 & 132.21 & 133.61 & 132.20 \\
6 & 109.29 & 104.42 & 109.29 \\
7 & 144.10 & 177.82 & 144.43 \\
$7^{\mathrm{a}}$ & 146.50 & 142.09 & 146.58 \\
$1^{\prime}$ & 134.32 & 123.67 & 132.11 \\
$2^{\prime}$ & 106.77 & 109.43 & 108.94 \\
$3^{\prime}$ & 147.87 & 146.58 & 146.66 \\
$4^{\prime}$ & 147.58 & 109.43 & 145.58 \\
$5^{\prime}$ & 108.04 & 114.44 & 114.07 \\
$6^{\prime}$ & 120.18 & 120.62 & 119.95 \\
$\alpha$ & 130.91 & 131.46 & 130.93 \\
$\beta$ & 123.44 & 124.36 & 123.45 \\
$\gamma$ & 17.87 & 18.41 & 18.33 \\
$\mathrm{CH}_{3}(3)$ & 18.33 & 9.57 & 17.56 \\
$\mathrm{OCH}_{3}(7)$ & 55.94 & 56.05 & 55.93 \\
$\mathrm{OCH}_{3}\left(3^{\prime}\right)$ & - & 56.09 & 55.97 \\
$\mathrm{OCH}_{2}$ & 101.06 & - & - \\
\hline & & &
\end{tabular}

record in $\mathrm{CDCl}_{3}$ at $300 \mathrm{MHz}$.

Eupomatenoid-7 (2) - Maroon-coloured powder, soluble in $\mathrm{CHCl}_{3}$, m.p. $100-104^{\circ} \mathrm{C},[\alpha]_{\mathrm{D}}{ }^{25^{\circ} \mathrm{C}}=-0.280(\mathrm{MeOH})$, IR: $v_{\max } 3429,2937,2849,1725,1604,1513,1452,1371$, 1267, 1221, 1147 and 1056. IE-MS: $m / z$ (rel. int.) 324 (100), 309 (20), 293 (15), 123 (6), 91 (9), 77 (5) and 31 (15).

Licarin A (3) - White powder, soluble in $\mathrm{CHCl}_{3}$, m.p. $107-110^{\circ} \mathrm{C},[\alpha]_{\mathrm{D}}{ }^{25^{\circ} \mathrm{C}}=-0.15(\mathrm{MeOH}), \mathrm{IR}: v_{\max } 3541,2938$, 1673, 1608, 1496, 1269 and 1143. IE-MS: $m / z$ (rel. int.) 326 (100), 311 (20), 308(7), 295 (5), 202 (10), 123 (8), 91 (10), $77(8)$ and 31 (25).

Mycobacterium strains - The following mycobacteria from the American Type Culture Collection (ATCC) were used: M. tuberculosis H37Rv (27294); mono-resistant strains: H37Rv isoniazid-resistant (35822), H37Rv streptomycin-resistant (35820), H37Rv rifampicin-resistant (35838) and H37Rv ethambutol-resistant (35837); $M$. avium (35717) and Mycobacterium smegmatis (35798). In addition, drug-resistant $M$. tuberculosis clinical isolates (12 strains) obtained from Mexican patients with pulmonary disease were also tested. Drug-resistant $M$. tuberculosis clinical isolates were selected based on their drug susceptibility patterns against antimycobacterial drugs employing the microdilution alamar blue assay (MABA) test. In addition, the following clinical or environmental non-TB mycobacteria isolates were included: Mycobacterium chelonae, Mycobacterium fortuitum and Mycobacterium non-chromogenicum. The strains were cultured in Middlebrook 7H9 broth supplemented with 10\% OADC enrichment (Becton Dickenson, USA) at $37^{\circ} \mathrm{C}$ until a logarithmic growth phase was achieved. $M$. tuberculosis and non-TB mycobacteria were diluted in $7 \mathrm{H} 9$ at the ratios of 1:20 and 1:50, respectively. Bacterial suspensions were fresh when utilized in the assays.

Antimycobacterial assay - Extracts, fractions and the pure compounds were evaluated by the previously described MABA assay (Jimenez-Arellanes et al. 2003, 2007). Briefly, samples were dissolved in dimethyl sulfoxide (DMSO) $(20 \mathrm{mg} / \mathrm{mL})$ under sterile conditions. Serial two-fold dilutions of each sample (range, 100-3.12 $\mu \mathrm{g} / \mathrm{mL}$ ) were prepared to a final volume of $100 \mu \mathrm{L}$ with $7 \mathrm{H} 9$ broth and $100 \mu \mathrm{L}$ of each mycobacterium suspension was added to 96-well sterile microplates (Nunc). For M. tuberculosis, plates were incubated at $35^{\circ} \mathrm{C}$ during five days, whereas non-TB mycobacteria were incubated for two days. MIC is expressed as the lowest concentration of the compound that causes $99 \%$ inhibition of mycobacterium growth. All assays were run in duplicate and streptomycin $(0.5 \mu \mathrm{g} / \mathrm{mL}$, Sigma), isoniazid $(0.06 \mu \mathrm{g} / \mathrm{mL}$, Sigma) and rifampicin $(0.1$ $\mu \mathrm{g} / \mathrm{mL}$, Sigma) were utilized as positive controls.

Cytotoxicity assay - The assay was carried out in a J774A.1 murine macrophage cell line (ATCC HB-197) using the trypan blue exclusion test. Briefly, purified neolignans were dissolved in DMSO at a concentration of $20 \mu \mathrm{g} / \mathrm{mL}$. Cells were grown in 24-well plates using DMEM supplemented with 10\% foetal bovine serum (FBS) and antibiotics. Immediately prior to testing, monolayers were washed with warm Hanks' balanced salt solution. Serial two-fold dilutions of each compound were prepared in DMEM supplemented with 10\% FBS (1-1/16 of MIC against $M$. tuberculosis H37Rv) and 1 $\mathrm{mL} /$ well of each dilution was added. To evaluate cell viability, controls were included in the microplate by adding DMEM media with DMSO; cell viability was determined after a 24-h incubation period. Trypan blue solution was added and the percentage of viable cells was calculated to determine the cytotoxic index $\left(\mathrm{IC}_{50}\right)$. The assay was run in triplicate.

Acute toxicity in mice - Male Balb/c mice $(22 \pm 2.2 \mathrm{~g})$ were used to determine the acute toxicity parameter following the methodology previously described by Lorke (1983) and according to the guidelines of the local Ethical Committee for Experimentation in Animals. Animals were maintained under standard environmental conditions at 12-h light/dark photoperiods with free access to food and water. Mice were randomly divided into five groups of three animals each. Group 1 received the control vehicle (Tween 20: $\mathrm{H}_{2} \mathrm{O} 2: 8$ ), while Groups 2-5 were treated orally with the crude extract at doses of 0.6, 1.0, 1.6 and $2.9 \mathrm{~g} / \mathrm{kg}$. The same design was employed to test the most active primary fraction (F8-F11) and the pure compound (licarin A). All samples were solubilized in Tween 20: $\mathrm{H}_{2} \mathrm{O}$ (2:8) and were intragastrically administered in a volume that was less than $10 \mathrm{~mL} / \mathrm{kg}$ of body weight. Treatment response was monitored at 1, 2, 4, 6 and $24 \mathrm{~h}$ and daily for 14 days, registering any signal of toxicity. At the end of the experimental period, the animals were sacrificed in a $\mathrm{CO}_{2}$ chamber to obtain the internal organs (lung, kidney, heart, spleen and liver) for pathological analysis. 


\section{RESULTS}

Chemical characterization of the isolated neolignans - The three neolignans were characterized by comparing spectral data (Tables I, II) with those previously reported in the literature (Enriquez et al. 1984) and the respective molecular structures of the compounds are illustrated in Fig 1.

Biological evaluation - As shown in Table III, a MIC of $50 \mu \mathrm{g} / \mathrm{mL}$ was determined for the hexanic crude extract against $M$. tuberculosis $\mathrm{H} 37 \mathrm{Rv}$ and $M$. avium. Primary fractionation yielded F8-F11 as the most active fractions, with MIC's of $12.5-50 \mu \mathrm{g} / \mathrm{mL}$ against M. tuberculosis $\mathrm{H} 37 \mathrm{Rv}$ strains and 12.5-100 $\mu \mathrm{g} / \mathrm{mL}$ against $M$. avium. These fractions, as well as F5-F7, were active against all tested mono-resistant strains of H37Rv and MDR M. tuberculosis clinical isolates (SIN3, SIN4, MMDO and HG8) and the MIC values obtained ranged from 12.5-50 $\mu \mathrm{g} / \mathrm{mL}$ (Table IV). In addition, fractions F8-F11 inhibited the growth of NTM as follows: $M$. non-chromogenicum $(\mathrm{MIC}=25 \mu \mathrm{g} / \mathrm{mL})$ and $M$. smegmatis, $M$. chelonae and M. fortuitum (MIC $=50 \mu \mathrm{g} / \mathrm{mL})$; the fractions were less active against $M$. avium ( $\mathrm{MIC}=100 \mu \mathrm{g} / \mathrm{mL})$. By contrast, fractions F5F7 were highly active against $M$. non-chromogenicum $(\mathrm{MIC}=12.5 \mu \mathrm{g} / \mathrm{mL})$ (Table V).

Antimycobacterial activity of the pure isolated compounds is shown in Table VI. Licarin B (1) was moderately active against $\mathrm{H} 37 \mathrm{Rv}$ and against mono-resistant variants (MICs, 25-50 $\mu \mathrm{g} / \mathrm{mL}$ ), but was highly active against the majority of MDR M. tuberculosis clinical isolates tested (with MIC values ranging from 12.5-50 $\mu \mathrm{g} / \mathrm{mL}$ ). Eupomatenoid-7 (2) was active against H37Rv strains (MIC $=25 \mu \mathrm{g} / \mathrm{mL}$ ), the four mono-resistant variants of $\mathrm{H} 37 \mathrm{Rv}$ and three of the MDR clinical isolates tested (MIC values ranging from $12.5-25 \mu \mathrm{g} / \mathrm{mL}$ ). The most clinically relevant activity of this compound ( $\mathrm{MIC}=6.25 \mu \mathrm{g} / \mathrm{mL}$ ) was against an $M$. tuberculosis clinical isolate (SIN4) that is resistant to first- and second-line drugs (Table VI).
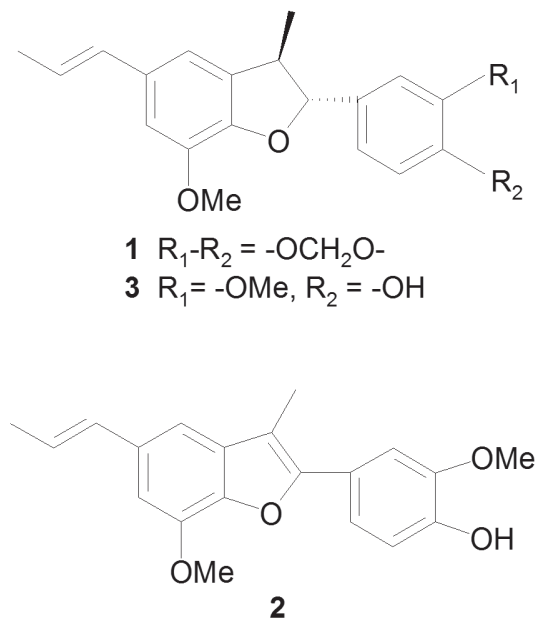

Chemical structures of the active neolignans (1-3) from Aristolochia taliscana.
TABLE III

Antimycobacterial activity of the hexanic extract and primary fractions from Aristolochia taliscana

\begin{tabular}{lcc}
\hline & \multicolumn{2}{c}{$\begin{array}{c}\text { Minimum inhibitory concentrations } \\
(\mu \mathrm{g} / \mathrm{mL})\end{array}$} \\
\cline { 2 - 3 } Sample & $\begin{array}{c}\text { Mycobacterium } \\
\text { tuberculosis } \mathrm{H} 37 \mathrm{Rv}\end{array}$ & $\begin{array}{c}\text { Mycobacterium } \\
\text { avium }\end{array}$ \\
\hline Hexanic extract & 50 & 50 \\
F1 & $\mathrm{ND}$ & $\mathrm{ND}$ \\
F2 & 100 & 200 \\
F3 & $\mathrm{ND}$ & $\mathrm{ND}$ \\
F4 & 200 & 200 \\
F5-F7 & 100 & 200 \\
F8 & 50 & 100 \\
F9 & 25 & 100 \\
F10 & 12.5 & 12.5 \\
F11 & 50 & 50 \\
F12 & 200 & 100 \\
F13-F15 & 200 & 200 \\
\hline
\end{tabular}

ND: non determined.

TABLE IV

Activity of primary fractions against Mycobacterium tuberculosis $\mathrm{H} 37 \mathrm{Rv}$ (reference strain), its four monoresistant variants and against multidrug-resistant clinical isolates of $M$. tuberculosis

\begin{tabular}{lcc}
\hline M. tuberculosis & \multicolumn{2}{c}{ MIC $(\mu \mathrm{g} / \mathrm{mL})$} \\
\hline Monoresistant & F5-F7 & F8-F11 \\
INH-R & 25 & 25 \\
RIF-R & 50 & 25 \\
STR-R & 12.5 & 25 \\
EMB-R & 25 & 25 \\
Clinical isolates & & \\
SIN3 & 25 & 25 \\
SIN4 & 50 & 25 \\
MMDO & 12.5 & 25 \\
HG8 & 25 & 12.5 \\
\hline
\end{tabular}

EMB-R: ethambutol-resistant of M. tuberculosis H37Rv; INH$\mathrm{R}$ : isoniazid-resistant; MIC: minimum inhibitory concentrations; RIF-R: rifampicin-resistant; STR-R: streptomycin-resistant.

Finally, while licarin A (3) exhibited moderate activity against $M$. tuberculosis $\mathrm{H} 37 \mathrm{Rv}(\mathrm{MIC}=25 \mu \mathrm{g} / \mathrm{mL})$, this compound was highly active against all mono-resistant and MDR M. tuberculosis strains tested, with MIC's ranging from 3.12-12.5 $\mu \mathrm{g} / \mathrm{mL}$ (Table VI). Clinical isolates with highest sensitivity to this compound included MMDO, HG8 and SIN4. In addition, licarin A (3) inhibited the NTM $M$. avium, $M$. smegmatis, $M$. fortuitum (all with $\mathrm{MIC}=6.25$ $\mu \mathrm{g} / \mathrm{mL})$ and $M$. chelonae $(\mathrm{MIC}=3.12 \mu \mathrm{g} / \mathrm{mL})($ Table $\mathrm{V})$. 
TABLE V

Antimycobacterial effect of the primary fractions and the pure compounds against non-tuberculous Mycobacteria strains

\begin{tabular}{|c|c|c|c|c|c|}
\hline \multirow[b]{3}{*}{ Strain } & \multicolumn{5}{|c|}{$\mathrm{MIC}(\mu \mathrm{g} / \mathrm{mL})$} \\
\hline & \multicolumn{2}{|c|}{ Primary fractions } & \multicolumn{3}{|c|}{ Pure compounds } \\
\hline & F5-7 & F8-11 & 1 & 2 & 3 \\
\hline Mycobacterium non-chromogenicum & 12.5 & 25 & 12.5 & 25 & ND \\
\hline Mycobacterium smegmatis & $>200$ & 50 & $>200$ & 25 & 6.25 \\
\hline Mycobacterium fortuitum & $>200$ & 50 & $>200$ & 50 & 6.25 \\
\hline Mycobacterium chelonae & $>200$ & 50 & $>200$ & 25 & 3.12 \\
\hline Mycobacterium avium & $>200$ & 100 & $>200$ & 50 & 6.25 \\
\hline
\end{tabular}

MIC: minimum inhibitory concentrations; ND: non determined.

TABLE VI

Antimycobacterial activity of the pure compounds from Aristolochia taliscana against Mycobacterium tuberculosis H37Rv and of the clinical isolates of multidrug-resistant $M$. tuberculosis

\begin{tabular}{|c|c|c|c|c|}
\hline \multirow{2}{*}{$\frac{\text { Strain }}{\text { M. tuberculosis }}$} & \multirow[t]{2}{*}{ Drug resistance pattern ${ }^{a, b}$} & \multicolumn{3}{|c|}{$\begin{array}{l}\text { MIC of pure compounds } \\
(\mu \mathrm{g} / \mathrm{mL})\end{array}$} \\
\hline & & 1 & 2 & 3 \\
\hline $\mathrm{H} 37 \mathrm{Rv}$ & INH, RIF, STR, EMB susceptible & 50 & 25 & 25 \\
\hline \multicolumn{5}{|l|}{ Monoresistant } \\
\hline INH-R & & 25 & 25 & 3.12 \\
\hline RIF-R & & 50 & 12.5 & 6.25 \\
\hline STR-R & & 25 & 25 & 3.12 \\
\hline EMB-R & & 25 & 25 & 6.25 \\
\hline \multicolumn{5}{|l|}{ Clinical isolates } \\
\hline MMDO & INH, EMB & 12.5 & 12.5 & 3.12 \\
\hline MTY650 & STR, INH & 12.5 & 50 & 6.25 \\
\hline MTY663 & STR, INH, RIF, EMB, PZA & 12.5 & 50 & 12.5 \\
\hline MTY675 & STR, INH, EMB & 12.5 & 50 & 12.5 \\
\hline MTY282 & STR, INH, EMB, PZA & 12.5 & 50 & 12.5 \\
\hline HG8 & EMB, CLR, ETH & 25 & 25 & 3.12 \\
\hline SIN3 & STR, INH, RIF, EMB, RFB, CLR, ETH & 25 & 25 & 6.25 \\
\hline MTY234 & STR, INH, RIF, PZA & 25 & 50 & 12.5 \\
\hline MTY112 & STR, INH, RIF, EMB & 25 & 50 & 12.5 \\
\hline MTY559 & STR, EMB & 25 & 50 & 12.5 \\
\hline SIN4 & STR, INH, RIF, EMB, RFB, ETH, OFX & 50 & 6.25 & 3.12 \\
\hline MTY172 & INH, PZA & 50 & 50 & 12.5 \\
\hline
\end{tabular}

$a$ : clinical isolates resistant to: streptomycin (STR), isoniazid (INH), rifampicin (RIF), ethambutol (EMB), rifabutin (RFB), ethionamide (ETH), clarithromycin (CLR), ofloxacin (OFX), pyrazinamide (PZA); $b$ : resistant pattern was determined by the microdilution alamar blue assay. MIC: minimum inhibitory concentrations.

Cytotoxicity assay of the pure neolignans on murine macrophage J774A.1 cell line yielded values of $\mathrm{IC}_{50}=$ $6.25 \mu \mathrm{g} / \mathrm{mL}$ for licarin $\mathrm{A}$ and $\mathrm{B}$ and $\mathrm{IC}_{50}=3.12 \mu \mathrm{g} / \mathrm{mL}$ for eupomatenoid-7. The acute toxicity of the crude extract, F8-F11 and its most active component, licarin A, determined in mice was $>1.706 \mathrm{mg} / \mathrm{kg}$.

\section{DISCUSSION}

TB is a severe global health problem and the search for novel therapeutic molecules is a necessity due to the appearance of resistance to the anti-mycobacterial drugs currently in use (Cantrell et al. 2001, O'Brien \& Spigelman 2005, Tomioka 2006, Gutiérrez-Lugo \& 
Bewley 2008). Medicinal plants comprise a promising natural source for the discovery of anti-TB drugs and the in vitro activity of several secondary metabolites has already been recognized. At present, 12-demethylmulticauline isolated from Salvia multicaulis (MIC= $0.46 \mu \mathrm{g} / \mathrm{mL}$ ), micromolide from Micromelum hirsutum $(\mathrm{MIC}=1.5 \mu \mathrm{g} / \mathrm{mL})$ and $(E)$-phytol from Leucas volkensii ( $\mathrm{MIC}=2 \mu \mathrm{g} / \mathrm{mL}$ ) are the most highly active compounds reported against M. tuberculosis H37Rv (Cantrell et al. 2001). Unfortunately, little information is available concerning the activity of natural compounds against MDR M. tuberculosis strains (Newton et al. 2002, Gibbons et al. 2003, Luna-Herrera et al. 2007).

While the use of Aristolochia species has been discussed extensively because of its content of aristolochic acid (Chen et al. 2007), this toxic compound was not detected in A. taliscana-root hexane extract. Moreover, the $\mathrm{LD}_{50}$ for the hexanic extract determined in mice was $>1706 \mathrm{mg} / \mathrm{kg}$. When evaluating this extract against $M$. tuberculosis $\mathrm{H} 37 \mathrm{Rv}$ and $M$. avium, moderate in vitro activity $(\mathrm{MIC}=50 \mu \mathrm{g} / \mathrm{mL}$ ) was determined. Activity against $M$. avium is of interest because currently, there is a high frequency of TB cases associated with this species in HIV/AIDS cases.

Bioguided fractionation of the extract led to the isolation of the previously identified neolignans licarin B, eupomatenoid-7 and licarin A (Enriquez et al. 1984, Abe et al. 2002). While several biological effects (antibacterial, antioxidant, anticancer, trypanocidal, neuroprotective, insecticidal and anti-inflammatory) of these compounds have been reported, to our knowledge, this is the first report on their anti-TB activity (Tsai et al. 2001, Abe et al. 2002, Lee et al. 2004, Ma et al. 2004, 2005, Park et al. 2004, Saleem et al. 2005).

Licarin A $\left(\mathrm{LD}_{50}>1706 \mathrm{mg} / \mathrm{kg}\right)$ displayed the most potent effect against all tested mono-resistant strains of $\mathrm{H} 37 \mathrm{Rv}$ and MDR clinical isolates of M. tuberculosis (MIC's ranging from 3.12-12.5 $\mu \mathrm{g} / \mathrm{mL}$ ). Likewise, licarin A was active against the non-TB mycobacteria $M$. avium, M. chelonae, M. fortuitum and M. smegmatis (MICs ranging from 3.12-6.25 $\mu \mathrm{g} / \mathrm{mL}$ ). A drug that is able to inhibit MDR M. tuberculosis and M. avium growth, such as licarin A, would be of extremely high value in the clinic, particularly in cases of HIV/AIDS and MDR/XDR.

Lignans are well-known secondary metabolites because of the cytotoxic effect they produce in several cell lines (Tsai et al. 2001, Park et al. 2004, Kong et al. 2005). The cytotoxic activity of licarin A has also been reported against P-388, KB16 and HT-29 cell lines (Tsai et al. 2001) and this activity for licarin B $(100 \mu \mathrm{M})$ has been described against the human promyelocytic leukaemia HL-60 cells, as it is the compound inactive for caspase-3 activation. Meanwhile licarin A induces an apoptotic effect by means of caspase-3 activation (Park et al. 2004). On the other hand, Lee et al. (2004) reported that licarin $\mathrm{A}$ is a potent inhibitor of phospholipase $\mathrm{C} \gamma 1$ (PLC $\gamma 1$ ) with an $\mathrm{IC}_{50}=15.8 \pm 1.3 \mu \mathrm{M}$ and that it exerts antiproliferative effects against three human cancer cell lines [A-549 (lung), MCF7 (breast) and HCT-15 (colon)], suggesting the use of licarin A as a cancer chemotherapeutic and chemopreventive agent (Lee et al. 2004, Park et al. 2004). The cytotoxicity of $A$. taliscana-isolated neolignans on murine macrophages was $\mathrm{IC}_{50}=3.25$ $6.25 \mu \mathrm{g} / \mathrm{mL}$; these values were similar to those determined for the MIC parameter.

The results obtained here permit us to suggest further biological evaluation of the effect of licarin A against macrophages infected with MDR M. tuberculosis, to determine the compound's intracellular activity.

In conclusion, a low-toxicity neolignan was isolated from the hexane extract of $A$. taliscana roots, structurally identified as licarin A and shown to be the most active compound against all mycobacteria tested. Licarin A is a new prototype molecule that exerts a relevant biological effect against the mycobacteria responsible for MDR-TB, a pandemic that is increasing at present and represents a serious health problem worldwide. In vivo experimental studies are in progress to establish the antiTB potential of this compound.

\section{REFERENCES}

Abe F, Nagafuji S, Yamauchi T, Okade H, Maki J, Higo H, Akahane H, Aguilar A, Jimenez-Estrada M, Reyes-Chilpa R 2002. Trypanocidal constituents in plants 1 . Evaluation of some Mexican plants for their trypanocidal activity and active constituents in guaco roots of Aristolochia taliscana. Biol Pharm Bull 25: 1188-1191.

Cantrell CL, Franzblau SG, Fischer NH 2001. Antimycobacterial plants terpenoids. Planta Med 67: 685-694.

Chen SM, Fan MY, Tseng CC, Ho Y, Hsu KY 2007. Pharmacokinetics and nephrotoxicity of aristolochic acid in rabbits. Toxicon 50: $180-188$.

Copp BR, Pearce AN 2007. Natural product growth inhibitors of $M y$ cobacterium tuberculosis. Nat Prod Rep 24: 278-297.

Díaz JL 1976. Usos de las plantas medicinales de México. Monografías cientificas III, 1st ed., IMEPLAM, México, 204 pp.

Enriquez RG, Chavez MA, Reynolds WF 1984. Phytochemical investigation of plants of the genus Aristolochia. 1. Isolation and NMR spectral characterization of eupomatenoid derivatives. J Nat Prod 47: 896-899.

Gibbons S, Fallah F, Wright CW 2003. Cryptolepine hydrochloride: a potent antimycobacterial alkaloid derived from Cryptolepis sanguinolenta. Phytother Res 17: 434-436.

Gutierrez-Lugo MT, Bewley CA 2008. Natural products, small molecules and genetics in tuberculosis drug development. $J$ Med Chem 51: 2606-2612.

Jain A, Mondal R 2008. Extensively drug-resistant tuberculosis: current challenges and threats. FEMS Immunol Med Microbiol 53: $145-150$.

Jimenez-Arellanes A, Meckes M, Ramirez R, Torres J, Luna-Herrera $\mathrm{J}$ 2003. Activity against multidrug-resistant Mycobacterium tuberculosis in Mexican plants used to treat respiratory diseases. Phytother Res 17: 903-908.

Jimenez-Arellanes A, Meckes M, Torres J, Luna-Herrera J 2007. Antimycobacterial triterpenoids from Lantana hispida (Verbenaceae). J Ethnopharmacol 111: 202-205.

Kong ZL, Tzeng SG, Liu YC 2005. Cytotoxic neolignans: an SAR study. Bioorg Med Chem Lett 15: 163-166.

Lee J, Kim J, Yu Y, Kin Y 2004. Inhibition of phospholipase C gamma 1 and cancer cell proliferation by lignans and flavans from Machilus thunbergii. Arch Pharm Res 27: 1043-1047. 
Lorke D 1983. A new approach to partial acute toxicity testing. Arch Toxicol 54: 275-287.

Luna-Herrera J, Costa MC, Gonzalez HG, Rodrigues AI, Castilho PC 2007. Synergistic antimycobacterial activities of sesquiterpene lactones from Laurus spp. J Antimicrob Chemother 59: 548-552.

Ma CJ, Kim SR, Kim J, Kim YC 2005. Meso-dihydroguaiaretic acid and licarin A of Machilus thunbergii protect against glutamateinduced toxicity in primary cultures of rat cortical cells. $\mathrm{Br} J$ Pharmacol 146: 752-759.

Ma CJ, Sung SH, Kim YC 2004. Neuroprotective lignans from the bark of Machilus thunbergii. Planta Med 70: 79-80.

Newton SM, Lau C, Gurcha SS, Besra GS, Wright CW 2002. The evaluation of forty-three plant species for in vitro antimycobacterial activities, isolation of active constituents from Psoralea corylifolia and Sanguinaria canadensis. J Ethnopharmacol 79: 57-67.

O'Brien R, Spigelman M 2005. New drugs for tuberculosis: current status and future prospects. Clin Chest Med 60: 327-340.
Park BY, Min BS, Kwon OK, Oh SR, Ahn KS, Kim TJ, Kim DY, Bae K, Lee HK 2004. Increase of caspase-3 activity by lignans from Machilus thunbergii in HL-60 cells. Biol Pharm Bull 27: 1305-1307.

Rivers EC, Mancera RL 2008. New anti-tuberculosis drugs with novel mechanisms of action. Curr Med Chem 15: 1956-1957.

Rodriguez JC, Garcia-Pachon E, Ruiz M, Royo G 2006. Drug susceptibility of the Mycobacterium genus in vitro test and clinical implications. Curr Clin Pharmacol 1: 277-279.

Saleem M, Kim HJ, Ali MS, Lee YS 2005. An update on bioactive plant lignans. Nat Prod Rep 22: 696-616.

Tomioka H 2006. Current status of some antituberculosis drugs and the development of new antituberculous agents with special reference to their in vitro and in vivo antimicrobial activities. Curr Pharm Des 12: 4047-4070.

Tsai IL, Chen JH, Duh CY, Chen IS 2001. Cytotoxic neolignans and butanolides from Machilus obovatifolia. Planta Med 67: 559-561.

Zager EM, McNerney R 2008. Multidrug-resistant tuberculosis. BMC Infect Dis 8: 10 . 